\title{
Associated Risk Factors for the Development of Extensively Resistant Pulmonary Tuberculosis in the First Level of Health Care: From a Public Health Perspective
}

\author{
Mauricio Mamani*,1, Mario Chauca², Edward Huamani ${ }^{3}$, Richard Gonzales ${ }^{3}$ \\ ${ }^{1}$ Universidad Privada San Juan Bautista, Lima, 15067, Perú \\ ${ }^{2}$ Universidad Ricardo Palma, Lima, 15039, Perú \\ ${ }^{3}$ Federico Villarreal National University, Lima, 15088, Perú
}

\begin{tabular}{l} 
A R T I C L E I N F O \\
\hline Article history: \\
Received: 09 July, 2021 \\
Accepted: 11 November, 202 \\
Online: 17 December, 2021 \\
\hline Keywords: \\
Risk factor \\
Extensively drug-resistant \\
Tuberculosis
\end{tabular}

\section{Introduction}

Tuberculosis (TB) is a disease caused by bacteria corresponding to the Mycobacterium tuberculosis complex, which usually attacks the lungs, but are not exclusive to them, is considered infectious to have the ability to be transmitted from a sick person to a healthy one, when the first expectora flugge drops in the form of aerosols [1].

TB, according to the World Health Organization (WHO), is among the ten leading causes of death worldwide, being in 2016 an approximate of 1.7 million deaths, of which 0.4 million had association with HIV, likewise, its statistics reveal that about 10.4 million individuals became ill with TB; as for its resistant forms, in the same year, an estimated $480,000(360,000$ to 600,000$)$ incident cases of MDRTB, where approximately 190,000 (120,000 to 260,000 ) would have died from this cause.

*Corresponding Author: Mauricio Mamani, maurim130@gmail.com

Only 123,000 cases were diagnosed, of which 12,240 developed XDR-TB (9\% of MDR-TB cases), where countries such as India, the People's Republic of China and the Russian Federation account for $50 \%$ of all extremely resistant cases; likewise, in Latin America, Peru, is among eight countries reporting presence of XDR-TB in a total of 117 cases, followed by Brazil, Mexico, Haiti, Argentina, Ecuador, Colombia and Bolivia [2], [3].

Likewise, in 2017 our country detected 31,518 incident cases of TB in all its forms, 27578 incident cases of pulmonary TB, 16 877 cases of smear-positive TB (FP), 1335 of MDR TB and 83 of XDRTB, representing TB morbidity statistics of 99.0 per 100 thousand inhabitants, an incidence of 86.7 per 100 thousand inhabitants and a smear-positive incidence of 53.0 per 100 thousand inhabitants. 
Peru accounts for $14 \%$ of the estimated cases of TB in the Region of the Americas; Metropolitan Lima and Callao report the highest percentage of TB patients in all its forms in the country with 64\%, in relation to multidrug-resistant TB (MDR-TB) it reaches $79 \%$ and extensively drug-resistant TB (XDR-TB) 70\%.

The Metropolitan Lima region is divided into four Integrated Health Network Directorates (DIRIS), which are responsible for the overall health of the population. The Lima City DIRIS is one of the main TB hotspots, as it has the highest concentration of TB cases in all its forms and resistances [4], [5].

The growing incidence of primary resistance and acquired resistance to XDR-TB in the DIRIS Lima Sur, which categorizes it as an epidemiological scenario of high risk of TB transmission, leads us to the particular analysis of the following factors: Prolonged contact with bacilliferous patients and substance abuse (tobacco, alcohol, drugs), whose development is carried out throughout our study and lead us to the decision to execute it and achieve the identification of those risk factors that are associated with the emergence of XDR-TB in MDR-TB patients, and that this useful and accurate information will support the approach of appropriate health policies in order to decrease the morbidity and mortality of the population vulnerable to MDR-TB and XDR-TB and contribute to the control and eradication of TB.

The study of risk factors is of great importance because they will allow to predict or prevent the development of TB disease, which are present in each individual and their variability is according to the socioeconomic development of their nation and the social status they have, so they can be classified into factors attributable to the individual, environmental factors or environment and socioeconomic factors [6].

Within the typology of risk factors they found two: the risk factors of the external environment or associated with the disease and the risk factors of the internal environment or predictors of a disease [7].

The consumption of harmful substances such as tobacco and alcohol are considered health risks and influence the therapeutic regimen of $\mathrm{TB}$, the former being a common risk factor and of great importance in $\mathrm{TB}$, with negative repercussions on public health [8].

The previous treatment of $\mathrm{TB}$ in its resistant forms as an incurable disease, together with the inadequate management of the follow-up of the cases, and an untimely and ineffective treatment, generated the mutation and appearance of new strains with greater resistance, thus the emergence of XDR-TB [9].

The deficiencies in the therapeutic regimen and its noncompliance, bring as a consequence the appearance of more resistant forms of TB (XDR-TB), which circulate freely in the community, increasing the transmission of these strains and their potential increase in morbidity and mortality [10]. XDR-TB statistics do not provide accurate official figures, but each country reports high and increasing figures for the lethality of this type of TB [11].

CAUSE EFFECT DIAGRAM

\begin{tabular}{lcc}
\hline Past & \multicolumn{1}{c}{ Present } & Future \\
\hline Cause & Study direction \\
Risk factor's & $\begin{array}{l}\text { Cases: Patients with presence of XDR-TB } \\
\text { Controls: Patients without the presence of XDR-TB }\end{array}$
\end{tabular}

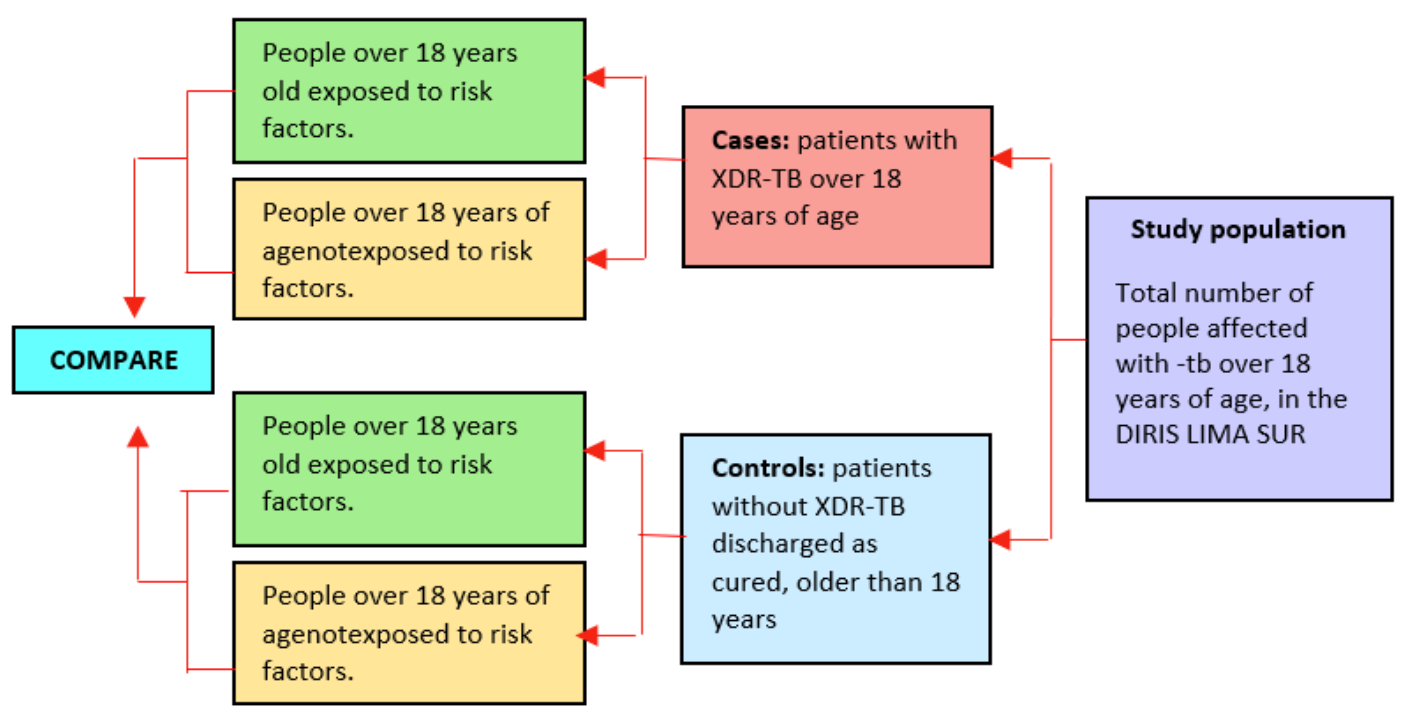

Figure 1: Cause Effect Diagram 
The progressive emergence of XDR-TB is of great concern because of its contagiousness and the difficulty to combat and control, which classifies it as potentially irreversible, where the vulnerable population is the most affected, followed by the economically active, in addition to conditions such as previous history of having received treatment and epidemiological background that allow a mechanism of transmission to the person, family and community, exacerbating the deterioration of the health of the entire population; this situation leads to great repercussions not only at the individual level but economic and social for the country, considering it as a public health problem.

To date, XDR-TB remains in the new millennium, the most dangerous human infectious disease, generating high numbers of deaths in the world, however, the production of resistant strains, is not yet defined to what extent would constitute a health problem today, so this article represents the extension of the work originally presented at the 4th International Conference on Medical and Health Informatics [12].

\section{Analysis y Method}

\subsection{Type of research}

A retrospective case-control study was developed, with quantitative approach, observational and analytical level, where we identified the risk factors of extensively drug-resistant TB (XDR-TB), applying the epidemiological method [13], [14].

\subsection{Variables}

The factors are events or phenomena from different sources that predispose people, belonging to a certain region, whose effects could generate the initiation of a disease, that is, that individual who is exposed to a greater number of risk factors will have a greater chance of developing a disease in relation to another less exposed, therefore, will have a high health risk in contrast to one who is away from those factors. [7] A risk factor is an agent that interacts with others; it is a series of detectable particularities in an individual or group way in people, related to the possibility that they are potentiated in influencing the state of health of people. These factors are usually accompanied by three elements and an exposure that predisposes to the development of a certain result (a disease) [15].

Risk factors associated with XDR-TB: These are those characteristics discernible in individuals or groups that are associated with an increased likelihood of developing an unfavorable effect on their health. That is, the exposed individual contracts and develops extensively resistant tuberculosis (XDRTB), this has extended the pattern of resistance to at least two of the most effective drugs of each second line group: the fluoroquinolone group and the second-line injectable group; having among them ciprofloxacin, levofloxacin and moxifloxacin for the first group and amikacin, kanamycin or capreomycin for the second group respectively. [16]

Presence of XDR TB: patients diagnosed with XDR TB, with positive smear or culture results and with a susceptibility panel showing resistance to the most potent first-line antituberculotic drugs and to a fluoroquinolone and aminoglycoside as second-line drugs. TB in this form of presentation has virtually no cure, reflects a high mortality rate and keeps the same transmission mechanism as in its simple form, being its potential affected also their family and close environment [17].

\subsection{Population, sample and sampling}

The population confirmation for this study was 158 MDR-TB patients diagnosed between 2016 and 2017; and 24 cases who were diagnosed as XDR-TB under treatment. The study area covered health facilities belonging to the Directorate of Integrated Health Networks Lima South (DIRIS). This total was subdivided into two groups of cases and controls. Using Open Epi software, a sample of 24 cases and 48 controls was obtained for unpaired case-controls [18], [19]. For the control group, simple random probability sampling was used, because as this is a subgroup of the population, each constituent element has the same possibility of choice.

\subsection{Instruments}

The survey was used as a technique and the questionnaire as an instrument, which was applied to both groups: control and cases, in some cases support was sought from medical records, follow-up records, treatment cards and home visits for verification of the information. The validity of the instrument was obtained through expert judgment made up of thematic, methodological and statistical specialists with academic degrees of Doctorate, likewise, it was validated by the technical standard and in other research studies carried out in Peru [20] (The instrument has a reliability of 0.730 (acceptable higher than 0.600 ) for all items.

\subsection{Data collection and analysis procedure}

The study began by reviewing the MDR-TB and XDR-TB case follow-up books of thirty-five (35) health facilities of the DIRIS Lima Sur that have a National Health Strategy for the Prevention and Control of Tuberculosis (ESN-PCT), and then selected those patients who met the inclusion criteria and through home visits proceeded to the application of the instruments after informed consent of the participants, having knowledge of the objectives and aims of the study. The data collected were processed by means of the statistical software STATA version 15, and presented in tables, parameters or measures for a better description and analysis of each study variable. In the hypothesis testing, the Odds Ratio (OR) was used in both simple logistic regression and multivariate regression, with a confidence interval (CI) of 95\%.

\section{Result}

\subsection{Descriptive analysis}

Table 1: Distribution of sociodemographic factors of patients with XDR-TB and MDR-TB in DIRIS Lima Sur, 2017

\begin{tabular}{|c|c|c|c|c|c|c|c|}
\hline & & \multicolumn{2}{|c|}{ Cases } & \multicolumn{2}{|c|}{ Controls } & \multicolumn{2}{|c|}{ Total } \\
\hline & & $\mathrm{n}_{1}$ & $\%$ & $\mathrm{n}_{2}$ & $\%$ & $\mathrm{n}$ & $\%$ \\
\hline \multirow[t]{4}{*}{ Age } & $10-19$ & 1 & 4.2 & 4 & 8.3 & 5 & 6.9 \\
\hline & $20-25$ & 5 & 20.8 & 13 & 27.1 & 18 & 25.0 \\
\hline & $26-60$ & 17 & 70.8 & 25 & 52.1 & 42 & 58.3 \\
\hline & 61 to more & 1 & 4.2 & 6 & 12.5 & 7 & 9.7 \\
\hline
\end{tabular}




\begin{tabular}{|c|c|c|c|c|c|c|c|}
\hline \multirow[t]{2}{*}{ Genre } & Male & 14 & 58.3 & 23 & 47.9 & 37 & 51.4 \\
\hline & Female & 10 & 41.7 & 25 & 52.1 & 35 & 48.6 \\
\hline \multirow{4}{*}{$\begin{array}{l}\text { Level of } \\
\text { education }\end{array}$} & Primary & 5 & 20.8 & 17 & 35.4 & 22 & 30.6 \\
\hline & Secondary & 15 & 62.5 & 18 & 37.5 & 33 & 45.8 \\
\hline & $\begin{array}{l}\text { Technical } \\
\text { superior }\end{array}$ & 4 & 16.7 & 8 & 16.7 & 12 & 16.7 \\
\hline & $\begin{array}{l}\text { Superior } \\
\text { Univ. }\end{array}$ & 0 & 0.0 & 5 & 10.4 & 5 & 6.9 \\
\hline \multirow[t]{4}{*}{ Occupation } & $\begin{array}{l}\text { Does not } \\
\text { work or } \\
\text { study }\end{array}$ & 14 & 58.3 & 19 & 39.6 & 33 & 45.8 \\
\hline & Work & 7 & 29.2 & 16 & 33.3 & 23 & 31.9 \\
\hline & Study & 2 & 8.3 & 8 & 16.7 & 10 & 13.9 \\
\hline & Other & 1 & 4.2 & 5 & 10.4 & 6 & 8.3 \\
\hline
\end{tabular}

Source: DIRIS Lima Sur, 2017

Table 1 describes the sociodemographic factors of the patients enrolled in the study. It can be seen that the age from 26 to 60 years is found in $70.8 \%$ of the cases and $52.1 \%$ of the controls, $58.3 \%$ of the cases were males and $52.1 \%$ of the controls were females, the secondary education level is found in $62.5 \%$ of the cases and $37.5 \%$ of the controls and the condition of not working or studying is found in $58.3 \%$ of the cases and $39.6 \%$ of the controls.

Table 2: Distribution of clinical factors of patients with XDR-TB and MDR-TB in DIRIS Lima Sur, 2017.

\begin{tabular}{|c|c|c|c|c|c|c|c|}
\hline & & \multicolumn{2}{|c|}{ Cases } & \multicolumn{2}{|c|}{ Controls } & \multicolumn{2}{|c|}{ Total } \\
\hline & & $\mathrm{n}_{1}$ & $\%$ & $\mathrm{n}_{2}$ & $\%$ & $\mathrm{n}$ & $\%$ \\
\hline \multirow{3}{*}{$\begin{array}{l}\text { Body Mass } \\
\text { Index }\end{array}$} & Normal & 17 & 70,8 & 32 & 66,7 & 49 & 68,1 \\
\hline & Overweight & 7 & 29,2 & 12 & 25,0 & 19 & 26,4 \\
\hline & Obesity & 0 & 0,0 & 4 & 8,3 & 4 & 5,5 \\
\hline \multirow{3}{*}{$\begin{array}{l}\text { Smear test } \\
\text { result (BK) }\end{array}$} & + & 9 & 37.5 & 25 & 52.1 & 34 & 47.2 \\
\hline & ++ & 7 & 29.2 & 13 & 27.1 & 20 & 27.8 \\
\hline & +++ & 8 & 33.3 & 10 & 20.8 & 18 & 25.0 \\
\hline \multirow{3}{*}{$\begin{array}{l}\text { Cultivation } \\
\text { result }\end{array}$} & + & 8 & 33.3 & 23 & 47.9 & 31 & 43.1 \\
\hline & ++ & 13 & 54.2 & 13 & 27.1 & 26 & 36.1 \\
\hline & +++ & 3 & 12.5 & 12 & 25.0 & 15 & 20.8 \\
\hline $\begin{array}{l}\text { Condition of } \\
\text { entry }\end{array}$ & Previously & 14 & 58.3 & 20 & 41.7 & 34 & 47.2 \\
\hline
\end{tabular}

Hematocrit Under result

Never

$\begin{array}{llllll}10 & 41.7 & 28 & 58.3 & 38 & 52.8\end{array}$

treated

\begin{tabular}{lcccccc} 
& 7 & 29,2 & 8 & 16,7 & 15 & 20,8 \\
Normal & & & & & & \\
& 17 & 70,8 & 40 & 83,3 & 57 & 79,2 \\
\hline
\end{tabular}

Source: DIRIS Lima Sur, 2017.

Table 2 shows that normal BMI was present in $70.8 \%$ of the cases and $66.7 \%$ of the controls, smear microscopy $(+)$ was present in $37.5 \%$ of the cases and $52.1 \%$ of the controls, on the other hand, the culture result for $54.2 \%$ of the cases was (++) and $47.9 \%$ of the controls, $(+)$. As for the admission condition, 58.3\% of the cases were previously treated and $41.7 \%$ of the controls were never treated. Normal hematocrit was present in $70.8 \%$ of cases and $83.3 \%$ of controls.

Table 3: Distribution of internal risk factors associated with MDR-TB in DIRIS Lima Sur, 2017.

\section{Cases Controls Total}

\begin{tabular}{|c|c|c|c|c|c|c|c|c|}
\hline & & & $\mathrm{n}_{1}$ & $\%$ & $\mathrm{n}_{2}$ & $\%$ & $\mathrm{n}$ & $\%$ \\
\hline $\begin{array}{l}\text { Harmful } \\
\text { Habits }\end{array}$ & $\begin{array}{l}\text { Alcohol } \\
\text { consumption }\end{array}$ & Yes & 5 & 20.8 & 6 & 12.5 & 11 & 15.3 \\
\hline
\end{tabular}

$$
\begin{array}{lllllll}
\text { No } & 19 & 79.2 & 42 & 87.5 & 61 & 84.7
\end{array}
$$

$\begin{array}{llllllll}\text { Drug Use } & \text { Yes } & 7 & 29.2 & 4 & 8.3 & 11 & 15.3\end{array}$

$\begin{array}{lllllll}\text { No } & 17 & 70.8 & 44 & 91.7 & 61 & 84.7\end{array}$

$\begin{array}{llllllll}\text { Tabaco use } & \text { Yes } & 4 & 16.7 & 4 & 8.3 & 8 & 11.1\end{array}$

History of comorbidities

Positive HIV $\begin{array}{llllllll}\text { serology } & \text { No } & 22 & 91.7 & 47 & 97.9 & 69 & 95.8\end{array}$

$\begin{array}{lllllll}\text { Yes } & 5 & 20.8 & 4 & 8.3 & 9 & 12.5\end{array}$

Diagnosis of $\begin{array}{llllllll}\text { Diabetes } & \text { No } & 19 & 79.2 & 44 & 91.7 & 63 & 87.5\end{array}$

$\begin{array}{lllllll}\text { Yes } & 2 & 8.3 & 0 & 0.0 & 2 & 2.8\end{array}$

Cortico prior

$\begin{array}{llllllll}\text { therapy } & \text { No } & 22 & 91.7 & 48 & 100.0 & 70 & 97.2\end{array}$ 
Source: DIRIS Lima Sur, 2017.

Table 3 shows the distribution of internal risk factors for the appearance of XDR-TB. Regarding harmful habits, 79.2\%, 70.8\% and $83.3 \%$ of the cases and $87.5 \%, 91.7 \%$ and $91.7 \%$ of the controls did not consume alcohol, drugs or tobacco, respectively.

The history of comorbidity such as a history of positive HIV serology, diagnosis of diabetes and use of corticotherapy were not present in the majority of cases or controls.

Table 4: Distribution of risk factors related to treatment history associated with MDR-TB in DIRIS Lima Sur, 2017.

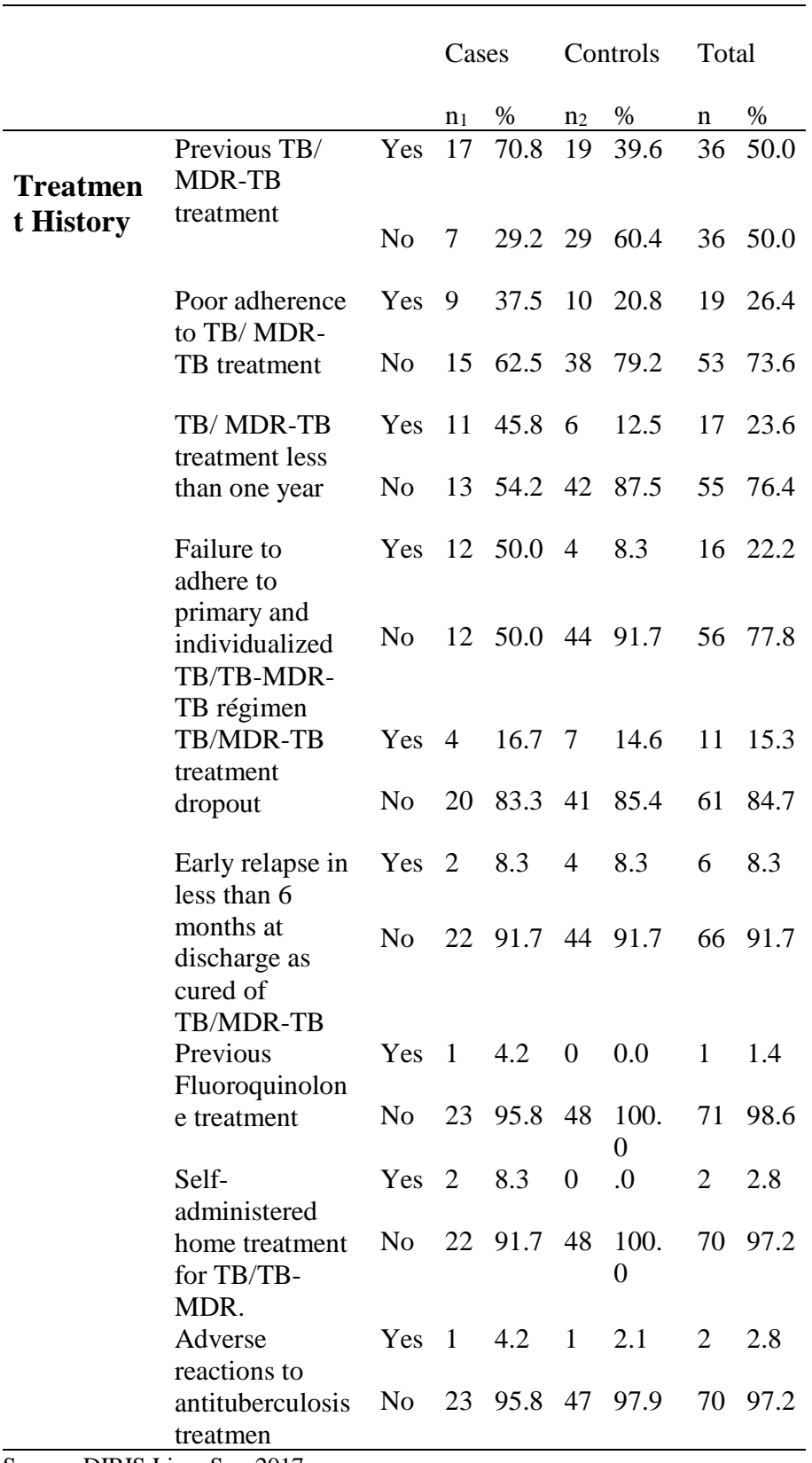

Source: DIRIS Lima Sur, 2017.

Table 4 shows that $70.8 \%$ of the cases were previously treated for TB/MDR-TB, $79.2 \%$ of the controls did not have poor adherence to TB/MDR-TB treatment. In $54.2 \%$ of the cases and $87.5 \%$ of the controls, no less than one year of previous treatment was required; $83.3 \%$ of the cases and $85.4 \%$ of the controls did not have a history of abandonment of MDR-TB/MDR-TB treatment; www.astesj.com no early relapse within 6 months of discharge as cured was present in $91.7 \%$ of cases and controls; self-administration of treatment was not present in $91.7 \%$ of cases and $100 \%$ of controls; and the presence of RAFAS was not present in the majority of cases and controls ( $>95 \%)$

Table 5: Distribution of external risk factors associated with MDR-TB in DIRIS Lima Sur, 2017.

\begin{tabular}{lllllllll} 
& & \multicolumn{3}{c}{ Cases } & \multicolumn{3}{c}{ Controls } & \multicolumn{2}{c}{ Total } \\
\hline $\begin{array}{l}\text { Contact } \\
\text { history }\end{array}$ & $\begin{array}{l}\text { Family } \\
\text { member at } \\
\text { home with } \\
\text { XDR- }\end{array}$ & Yes & 14 & 58.3 & 27 & 56.3 & 41 & 56.9 \\
& No & 10 & 41.7 & 21 & 43.8 & 31 & 43.1 \\
& $\begin{array}{l}\text { TB/MDR- } \\
\text { Had family } \\
\text { members who } \\
\text { died of XDR- } \\
\text { TB/MDR-TB }\end{array}$ & Yes & 10 & 41.7 & 7 & 14.6 & 17 & 23.6 \\
& No & 14 & 58.3 & 41 & 85.4 & 55 & 76.4
\end{tabular}

\begin{tabular}{|c|c|c|c|c|c|c|c|}
\hline Have you had & Yes & 11 & 45.8 & 25 & 52.1 & 36 & 50.0 \\
\hline $\begin{array}{l}\text { friends in the } \\
\text { neighborhood } \\
\text { with } \\
\text { tuberculosis? }\end{array}$ & No & 13 & 54.2 & 23 & 47.9 & 36 & 50.0 \\
\hline $\begin{array}{l}\text { Have you had } \\
\text { neighbors or }\end{array}$ & Yes & 5 & 20.8 & 2 & 4.2 & 7 & 9.7 \\
\hline $\begin{array}{l}\text { friends in the } \\
\text { neighborhood } \\
\text { who died from } \\
\text { TB? }\end{array}$ & No & 19 & 79.2 & 46 & 95.8 & 65 & 90.3 \\
\hline \multirow{2}{*}{$\begin{array}{l}\text { Prison history } \\
\text { for the past } \\
\text { two years. }\end{array}$} & Yes & 5 & 20.8 & 4 & 8.3 & 9 & 12.5 \\
\hline & No & 19 & 79.2 & 44 & 91.7 & 63 & 87.5 \\
\hline $\begin{array}{l}\text { Previously } \\
\text { worked in }\end{array}$ & Yes & 0 & 0.0 & 3 & 6.3 & 3 & 4.2 \\
\hline $\begin{array}{l}\text { hospital or was } \\
\text { a health } \\
\text { science student }\end{array}$ & No & 24 & 100.0 & 45 & 93.8 & 69 & 95.8 \\
\hline $\begin{array}{l}\text { Hospitalized in } \\
\text { the last two }\end{array}$ & Yes & 1 & 4.2 & 1 & 2.1 & 2 & 2.8 \\
\hline $\begin{array}{l}\text { years before } \\
\text { becoming ill } \\
\text { with TB, for } \\
\text { more than } 15 \\
\text { days. }\end{array}$ & No & 23 & 95.8 & 47 & 97.9 & 70 & 97.2 \\
\hline
\end{tabular}
Source: DIRIS Lima Sur, 2017.

Table 5 presents the external factors associated with XDR-TB. Intradomiciliary contact with XDRTB/MDR-TB was present in $58.3 \%$ of the cases and $56.3 \%$ of the controls; history of a deceased family member with XDR-TB/MDR-TB was not present in 58.3\% of the cases and $85.4 \%$ of the controls. The majority of cases and controls did not have out-of-home contact with TB, were not former prisoners did not work in health facilities, were not students of health sciences, and had not been hospitalized in the last two years for TB. 


\subsection{Hypothesis testing}

\section{General hypothesis}

H0: Risk factors are not significantly associated with extensively resistant tuberculosis in multidrug-resistant patients. in the Health Directorate Lima Sur, 2017.

H1: Risk factors are significantly associated with extensively resistant tuberculosis in multidrug-resistant patients. in Health Directorate Lima Sur, 2017.

The association of risk factors with the development of XDRTB was contrasted from the sub-hypotheses, to which each factor separately was applied simple logistic regression (bivariate) and multivariate, for subsequent determination of the existence or nonexistence of significant association; using the Odds Ratio (OR) with a confidence interval (CI) of $95 \%$ and considered as a statistically significant result at a level $\square=0.05$

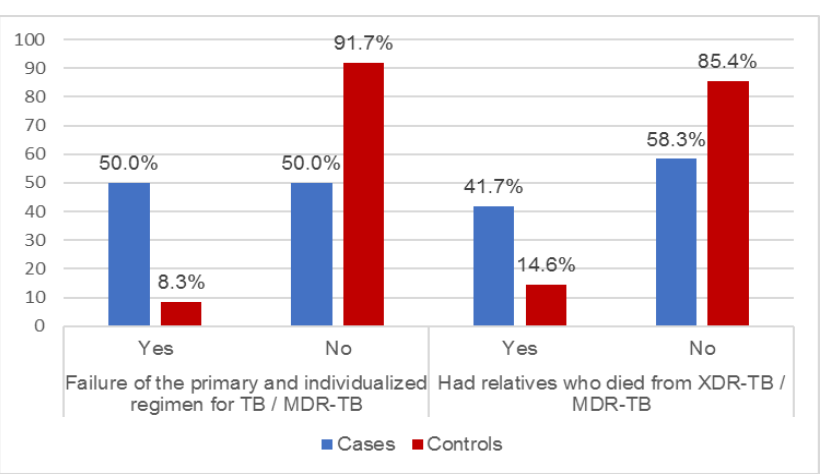

Figure 2: Factores de riesgo internos y externos asociados significativamente a la TB-XDR

According to the figure, $50 \%$ of the cases if they failed the primary and individualized scheme for TB / MDR-TB and 41.7\% of the cases if they had relatives who died from XDR-TB / MDRTB; in controls, $91.7 \%$ did not fail the primary and individualized regimen for MDR-TB / TB and 85.4\% had no relatives who died from XDR-TB / MDR-TB.

\section{Specific Hypothesis 1}

H0: Internal risk factors are not significantly associated with the presence of extensively drug-resistant tuberculosis in multidrug-resistant patients.

H1: Internal risk factors are significantly associated with the presence of extensively drug-resistant tuberculosis in multidrugresistant patients

Table 6 shows that the factors associated with XDR-TB in the DIRIS Lima Sur were: drug use, previous history of having used MDR-TB/TB treatment, having received MDR-TB treatment for less than one year and history of treatment failure for MDR$\mathrm{TB} / \mathrm{TB}$, since their p-value is $<0.05$, rejecting the $\mathrm{H} 0$ and concluding that these factors are significant. The multivariate analysis reaffirmed the influence of the variable: history of failure to primary and individualized treatment for MDR-TB/TB. In this sense: The odds of presenting XDR-TB in the group of cases with failure to the primary and individualized scheme for MDR-TB/TB is 6.81 times the odds of presenting XDR-TB. In the controls with primary and individualized TB/TB-MDR-TB scheme failure.
Table 6: Statistical test of internal risk factors associated with XDR-TB in DIRIS Lima Sur, 2017.

\begin{tabular}{|c|c|c|c|c|c|c|}
\hline & \multirow{2}{*}{$\begin{array}{c}\mathrm{p} \\
\text { value }\end{array}$} & \multicolumn{2}{|c|}{ Bivariate } & \multicolumn{2}{|c|}{ Multivariate } \\
\hline & & & OR & IC95\% & OR & IC95\% \\
\hline Harmful & $\begin{array}{l}\text { Alcohol } \\
\text { consumption }\end{array}$ & 0,354 & 1,84 & $\begin{array}{l}0,49- \\
6,79\end{array}$ & & \\
\hline \multirow[t]{2}{*}{ Habits } & Drug use & 0,021 & 4.53 & $\begin{array}{l}1,17- \\
17,47\end{array}$ & & \\
\hline & Tabaco use & 0,289 & 2,2 & $\begin{array}{c}0,49- \\
9,69\end{array}$ & & \\
\hline \multirow[t]{3}{*}{$\begin{array}{l}\text { History of } \\
\text { comorbidities }\end{array}$} & $\begin{array}{l}\text { Positive } \\
\text { serology for } \\
\text { HIV }\end{array}$ & 0,211 & 4,27 & $\begin{array}{l}0,37- \\
49,68\end{array}$ & & \\
\hline & $\begin{array}{l}\text { Diagnosis de } \\
\text { Diabetes } \\
\text { Mellitus }\end{array}$ & 0,131 & 2,89 & $\begin{array}{l}0,69- \\
11,98\end{array}$ & & \\
\hline & $\begin{array}{l}\text { Corticosteroid } \\
\text { therapy }\end{array}$ & $0,108 *$ & - & - & & \\
\hline \multirow[t]{9}{*}{$\begin{array}{l}\text { Treatment } \\
\text { History }\end{array}$} & $\begin{array}{l}\text { Previous TB/ } \\
\text { MDR-TB } \\
\text { treatment }\end{array}$ & 0,012 & 3,71 & $\begin{array}{l}1,29- \\
10,63\end{array}$ & & \\
\hline & $\begin{array}{l}\text { Poor adherence } \\
\text { to TB/ MDR- } \\
\text { TB treatment }\end{array}$ & 0,130 & 2,28 & $\begin{array}{c}0,77- \\
6,72\end{array}$ & & \\
\hline & $\begin{array}{l}\text { TB/ MDR-TB } \\
\text { treatment less } \\
\text { than one year }\end{array}$ & 0,002 & 5,92 & $\begin{array}{l}1,83- \\
19,15\end{array}$ & & \\
\hline & $\begin{array}{l}\text { Failure to } \\
\text { adhere to } \\
\text { primary and } \\
\text { individualized } \\
\text { TB/TB-MDR- } \\
\text { TB régimen }\end{array}$ & 0,000 & 11 & $\begin{array}{l}3,00- \\
40,33\end{array}$ & 6,81 & $\begin{array}{l}1,39- \\
33,27\end{array}$ \\
\hline & $\begin{array}{l}\text { TB/MDR-TB } \\
\text { treatment } \\
\text { dropout }\end{array}$ & 0,817 & 1,17 & $\begin{array}{c}0,31- \\
4,47\end{array}$ & & \\
\hline & $\begin{array}{l}\text { Early relapse in } \\
\text { less than } 6 \\
\text { months at } \\
\text { discharge as } \\
\text { cured of } \\
\text { TB/MDR-TB. }\end{array}$ & $0,108^{*}$ & 1 & $\begin{array}{l}0,17- \\
5,89\end{array}$ & & \\
\hline & $\begin{array}{l}\text { Previous } \\
\text { Fluoroquinolone } \\
\text { treatment }\end{array}$ & $0,333^{*}$ & - & - & & \\
\hline & $\begin{array}{l}\text { Self- } \\
\text { administered } \\
\text { home treatment } \\
\text { for TB/TB- } \\
\text { MDR. }\end{array}$ & $0,108^{*}$ & - & - & & \\
\hline & $\begin{array}{l}\text { Adverse } \\
\text { reactions to } \\
\text { antituberculosis } \\
\text { treatment }\end{array}$ & $0,559 *$ & 2,04 & $\begin{array}{l}0,12- \\
34,16\end{array}$ & & \\
\hline
\end{tabular}

Source: DIRIS Lima Sur, 2017

\section{Specific Hypothesis 2}

H0: External risk factors are not significantly associated with the presence of extensively drug-resistant tuberculosis in multidrug-resistant patients.

H1: External risk factors are significantly associated with the presence of tuberculosis. extensively resistant in multidrugresistant patients. 
Table 6: Statistical test of external risk factors associated with XDR-TB in DIRIS Lima Sur, 2017.

\begin{tabular}{|c|c|c|c|c|c|c|}
\hline & & \multirow[t]{2}{*}{$\begin{array}{l}\mathrm{p}- \\
\text { value }\end{array}$} & \multicolumn{2}{|c|}{ Bivariate } & \multicolumn{2}{|c|}{ Multivariate } \\
\hline & & & OR & IC95\% & OR & IC95\% \\
\hline \multirow[t]{7}{*}{$\begin{array}{l}\text { Contact } \\
\text { history }\end{array}$} & $\begin{array}{l}\text { Family } \\
\text { member at } \\
\text { home with } \\
\text { XDR- } \\
\text { TB/MDR-TB }\end{array}$ & 0,866 & 1,09 & $\begin{array}{c}0,40- \\
2,94\end{array}$ & & \\
\hline & $\begin{array}{l}\text { Had family } \\
\text { members } \\
\text { who died of } \\
\text { XDR- } \\
\text { TB/MDR-TB }\end{array}$ & 0,011 & 4,18 & $\begin{array}{l}1,34- \\
13,09\end{array}$ & 9,73 & $\begin{array}{l}2,00- \\
47,26\end{array}$ \\
\hline & $\begin{array}{l}\text { Have you had } \\
\text { neighbors or } \\
\text { friends in the } \\
\text { neighborhood } \\
\text { with } \\
\text { tuberculosis? }\end{array}$ & 0,617 & 0,78 & $\begin{array}{l}0,29- \\
2,08\end{array}$ & & \\
\hline & $\begin{array}{l}\text { Have you had } \\
\text { neighbors or } \\
\text { friends in the } \\
\text { neighborhood } \\
\text { who died } \\
\text { from TB? }\end{array}$ & 0,024 & 6,05 & $\begin{array}{l}1,08- \\
33,96\end{array}$ & & \\
\hline & $\begin{array}{l}\text { Prison history } \\
\text { for the past } \\
\text { two years. }\end{array}$ & 0,131 & 2,89 & $\begin{array}{l}0,69- \\
11,98\end{array}$ & & \\
\hline & $\begin{array}{l}\text { Previously } \\
\text { worked in } \\
\text { hospital or } \\
\text { was a health } \\
\text { science } \\
\text { student }\end{array}$ & $0,546^{*}$ & - & - & & \\
\hline & $\begin{array}{l}\text { Hospitalized } \\
\text { in the last } \\
\text { two years } \\
\text { before } \\
\text { becoming ill } \\
\text { with TB, for } \\
\text { more than } 15 \\
\text { days. }\end{array}$ & $0,559 *$ & 2,04 & $\begin{array}{l}0,12- \\
34,16\end{array}$ & & \\
\hline
\end{tabular}

Table 7 shows that the external factors associated with XDRTB in the DIRIS Lima Sur were: history of a family member who died of XDR-TB/MDR-TB and having friends or neighbors in the neighborhood who died of TB, due to their $\mathrm{p}$-value $<0.05$, rejecting the $\mathrm{HO}$ and concluding that these factors are significant. The multivariate analysis reaffirmed the influence of the variable: history of a family member who died from XDR-TB/MDR-TB. In this sense: The odds of presenting XDR-TB in the group of cases who had relatives who had died of XDR-TB/MDR-TB is 9.73 times the odds of presenting XDR-TB in the controls who had relatives who had died of XDR-TB/MDR-TB.

\section{Discussion}

When analyzing our results, we found that according to sociodemographic factors of the 72 patients with XDR-TB and MDR-TB in the DIRIS Lima Sur; taking into account the majority of cases, $70.8 \%$ are between 26 to 60 years old, 58.3\% are male, $62.5 \%$ have secondary school education and $58.3 \%$ neither work nor study. As for the majority of controls, 52.1\% were between 26 and 60 years of age, $52.1 \%$ were women, $45.8 \%$ had secondary education and $45.8 \%$ did not work or study. The results are similar in some respects to those of other studies in which the variables age, age, sex, sex, and age related variables were crossed. [21] Where the variables age, sex and occupation were crossed. Likewise with the study of [22] where the variables age, sex and occupation were considered as predictors of the appearance of XDR-TB and MDR-TB. It is also worth mentioning the study of [23] where they show age greater than or equal to 40 years as a significant protective factor. Another study by [24] Another study of the study of the study of the age of the cases shows an average age of 37 years for the case group and 38 years for the controls, as well as $56.2 \%$ and $66.7 \%$ for the male gender for cases and controls respectively.

The socioeconomic level of a person has an impact on morbidity and mortality in vulnerable population groups and therefore in their country. Studies have shown that a lower socioeconomic status has an impact on the mother's education and that a poor educational level is associated with increasing morbidity rates [25].

One of the great changes in the epidemiology of TB worldwide are the resistant forms of this disease, from mono-resistant TB to XDR-TB, constituting from a great challenge for public health to an incurable disease with very high lethality, especially if it is associated with HIV/AIDS.

The existence of factors such as those found in our study, for the group of cases with a history of a family member who died of XDR-TB, is 9.73 times more likely to develop XDR-TB and the history of having received previous anti-tuberculosis treatment is 6.81 times more likely to develop XDR-TB than in the control group. These epidemiological factors predispose morbidity and mortality in the economically active population.

The internal factors significantly associated with the development of XDR-TB were drug use, previous history of having received MDR-TB/TB treatment, having received previous MDR-TB treatment for less than one year, and multivariate analysis confirmed the significant influence of the variable failure to primary and individualized MDR-TB/TB treatment. The study of [20] study highlights that the failure of an antituberculosis treatment scheme consisting of drugs such as fluoroquinolone and a second-line injectable has a strong association with XDR-TB. Another study by [22] concludes that one of the factors associated with multidrug resistant TB is a history of previous TB treatment. Also in the research [26] also stated that problems or failure to adhere to treatment is more strongly associated with XDR-TB as well as inadequate screening, among others. Another study [21] highlights a history of anti-TB treatment as a risk factor for the development of MDR TB and XDR TB, and that failure to adhere to treatment regimens is strongly associated with XDR TB [9] is strongly associated with XDR-TB.

Regarding harmful habits, patients with a history of drug use have a higher risk of developing XDR-TB, results that are related to the study of [24] where he reaffirms drug addiction along with deterioration in adherence to treatment as risk factors for the 
presence of MDR-TB. The success of a TB control program and the health of the affected person will depend on the degree of adherence to the therapeutic regimen, which is one of the most important aspects in the management of resistant $\mathrm{TB}$, for which the interdisciplinary team of health institutions should formulate patient-centered and oriented strategies in order to seek adherence to supervised treatment and avoid irregularities, in partnership and involvement of grassroots organizations, social actors in the community, and community health workers [17].

The external factors with significant association to the development of XDR-TB found were extradomiciliary contact with someone who died of TB; and through multivariate analysis, the influence of the variable: family member who died of XDRTB/MDR-TB was reaffirmed, results that are coherent with the study of [23] study in relation to the occurrence of primary MDRTB in patients from Callao, ratifying as a risk factor having had contact with someone with MDR/XDR-TB and as a protective factor being younger than 40 years old. Other studies, such as [20] highlights as factors with a strong association to the development of XDR-TB the failure of a treatment scheme with second-line drugs and having a close relationship with someone affected by documented XDR-TB, [21] also mentions contact with MDR TB as a risk factor, and in the case-control study, the study also [27] also considers previous contact with MDRTB cases in both groups as a risk factor.

The contact is the person who establishes a close relationship with the affected person; therefore, an extra-domiciliary contact is comprised of partners, friends, neighbors and family members who have a regular relationship with the person with TB and who frequently visit the home. The primary practices for environmental control of TB and its resistant forms such as XDR is to ensure and maximize natural and cross ventilation in the environment, free of obstacles in the entrances, to ensure an exchange of air flow with a minimum of twelve air changes per hour and to ensure natural lighting, these strategies comprise primary prevention [17].

The next level of prevention is secondary, through early detection and timely treatment will ensure the cure and reduction of serious consequences of the disease, so in the case of TB, this is not aimed at reducing the incident cases but to reduce its severity (duration and complications) and lethality. In [28], Likewise, tertiary prevention aimed at rehabilitation seeks to reduce the complications of a disease through therapy and rehabilitative medicine, guaranteeing the reduction of sequelae, disabilities, and suffering, and promoting the adaptation of affected persons and their families to their environment. All these levels of prevention also include good quality medical care, which together will allow the individual to reintegrate into productive activities without being re-exposed to the same risk factors that contributed to getting sick [28].

Our findings showed that, despite the existence of a health strategy for the prevention and control of tuberculosis with defined objectives and treatment schemes approved by technical standards, there are risk factors that are associated with the emergence of extensively resistant $\mathrm{TB}$, which demonstrates deficiencies in the approach to people affected by tuberculosis, which goes beyond an exclusively health approach, but also demographic and social. This situation does not contribute to an adequate isolation of the index case, generating chains of multiplication and transmission of TB and MDR/XDR TB bacilli in the family nucleus and community. In addition, overcrowded public transportation puts at risk the other passengers who share the same reduced and unventilated space, under the same mechanism.

There are not enough human resources for the comprehensive care of TB patients, and the health personnel at the first level of care are responsible for the approach and management of TB, MDR-TB and XDR-TB cases, making early diagnosis and timely treatment of this complex disease difficult. These patients with MDR-TB and XDR-TB receive treatment divided into two doses, both in the morning and in the afternoon; however, most first-level health care institutions only provide care in the mornings, a situation that contributes to the large-scale increase in the morbidity of tuberculosis in the country.

\section{Conclusions}

There are risk factors that are significantly associated with the development of extensively resistant tuberculosis in multidrugresistant patients in the Directorate of Integrated Health Networks of Lima Sur, demonstrating that these factors were determinant for its appearance.

Multivariate analysis showed that the association of the internal risk factor: having failed the primary and individualized regimen for MDR-TB/TB is 6.81 times higher risk of developing XDR-TB/MDRTB than in those who did not fail.

The external risk factor: having a deceased family member with XDR-TB/MDR-TB is 9.73 times more likely to develop XDR-TB/MDR-TB than those without a deceased family history; this association was confirmed by multivariate analysis.

\subsection{Recommendations}

It is suggested to implement and train health professionals in the approach and comprehensive care of the person affected by tuberculosis, as well as in the sustainable work of adherence to supervised treatment.

Implement the family and community health program to reduce the epidemiological profile of tuberculosis as a key strategy in the Directorate of Integrated Health Networks in southern Lima. Also, promote research to develop new diagnostic and susceptibility panel tests and prioritize research with an epidemiological approach

\section{References}

[1] M. Raviglione, Tuberculosis: The Essentials, Fourth Edition. Boca Raton: CRC Press 2016.

[2] WHO. Implementation of the end of TB strategy. Genova: WHO 2016.

[3] OPS. Tuberculosis in the Region of the Americas. Retrieved February 28, 2015.

[4] OPS. Tuberculosis. Retrieved from https://bit.ly/2rf0xlG.

[5] MINSA. Tuberculosis intervention and control plan 2018 - 2020. Lima. Retrieved on May 10, 2018.

[6] J. Garcia, Tuberculosis and risk factors. Emerging diseases, 153, 2016.

[7] K. Colimon, Foundations of Epidemiology. Madrid: Diaz de Santos S.A 2008.

[8] WHO. World report on tuberculosis. Retrieved June 12, 2014, from http://www.who.int/mediacentre/factsheets/fs104/es/.N. Cao, M. Štěpnička, M. Burda, "Fuzzy Quantifiers and Compositions of Partial Fuzzy Relations Employing Dragonfly Algebras,” in 2019 IEEE International Conference on Fuzzy Systems (FUZZ-IEEE), 1-6, 2019, doi:10.1109/FUZZ- 
IEEE.2019.8858832.

[9] Y. Llamas, Extensively antibiotic-resistant tuberculosis (XDR-TB): therapies used successfully clinically to cure the disease. Journal of Clinical Research, 65(3), 255-262, 2013. DOI: 10.1016/j.ijantimicag.2009.12.019

[10] J. Robledo, Control of multidrug-resistant tuberculosis: a possible goal. Rev Biomedica, 39(3), 431-433, 2019. DOI: 10.2165/11595340-00000000000000

[11] M. Contrera, Drug-resistant tuberculosis: diagnosis and treatment. National Guide for e; tuberculosis management, 147, 2017.

[12] M. Mamani et al., Characterization of risk factors associated with tuberculosis. ICMHI 2020: Proceedings of the 4th International Conference on Health and Medical Informatics ( 230-234). Ibaraki-Japan: Association for Computing Machinery, 2014

[13] R. Bonita, Basic Epidemiology. Washington, D.C: PAHO, 2017.

[14] R. Hernandez et al., Research methodology (Sixth ed.). Mexico: McGraw Hill, 2018.

[15] CDC. Risk factors for tuberculosis. Obtained from the Center for the Control and Prevention of Nurses: https://www.cdc.gov/tb/esp/topic/basics/risk.htm.

[16] C. Daley, An Issue of Clinics in Chest Medicine. Pennsylvania: Elsevier Health Sciences, 2019.

[17] MINSA. Technical Health Standard for the comprehensive care of people affected by tuberculosis. Lima: MINSA, 2013.

[18] J. Kelsey, Methods in Observational Epidemiology. New York: Oxford University Press, 1986.
[19] J. Fleiss, J. Statistical Methods for Relationships and Proportions. New York: John Wiley and sons, 1981.

[20] M. Ticona, Extremely resistant tuberculosis (XDR-TB), history and current situation. Acta Med Per, 4, 25, 2008.

[21] Y. Libón, Risk factors for the development of multidrug-resistant tuberculosis in patients of the Hospital Nacional "Dos de Mayo. Ricardo Palma University, Lima, Lima, 2017.

[22] D. Asenjo, Factors associated with multidrug resistance in. patients diagnosed with tuberculosis Guillermo Almenara Irigoyen National Hospital. San Martin de Porres University, Lima, 2016.

[23] A. Avalos, Factors associated with primary multidrug-resistant tuberculosis in. An Fac med, 75, 233-246, 2016.

[24] Rodriguez. Risk Factors for Multidrug-resistant Pulmonary Tuberculosis in the La Libertad Region, Peru, 2013.

[25] J. Gofin, Global Community Health, principles and programs in the world. Madrid, 2012.

[26] Y. Gonzales, Extensively antibiotic-resistant tuberculosis (XDR-TB): therapies used successfully clinically to cure the disease. Clinical Research Rev., 60(3), 2011. DOI: 10.1016/j.ijantimicag.2009.12.019

[27] T. Chang et al., Risk factors in the appearance of multidrug resistance in patients with pulmonary tuberculosis. Rev medic panacea, 4(2), 31-35, 2014.

[28] OPS. Module of principles of epidemiology for the control of diseases (MOPECE) (Second ed.). Washington D.C .: OPC, 2011.

\section{Annexes}

\section{QUESTIONNAIRE TO DETECT RISK FACTORS ASSOCIATED WITH THE PRESENCE OF TB-XDR IN A FIRST LEVEL HEALTH CARE}

INSTITUTION - DIRIS LIMA SUR, 2017

I. Socio-demographic characteristics (Intervening variable)

A. Age (in years)

1) $10-19$

2) $20-25$

3) $26-60$

4) 61 plus

C. Level of education

1) Primary

2) Secondary

D. Occupation

1) Not working, not studying

2) Works

E. BMI category.

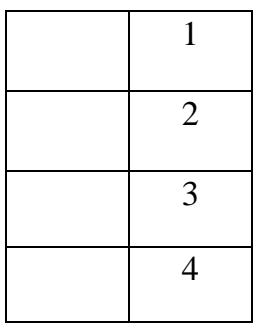

1) Male

2) Female

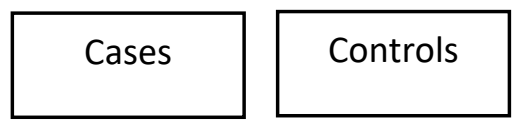

B. Genero

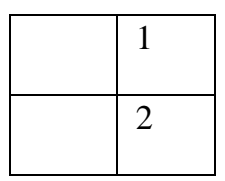

3) Technical superior

4) Superior Univ.

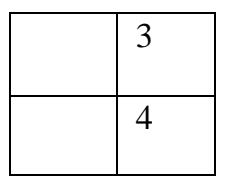

3) Study

4) Other

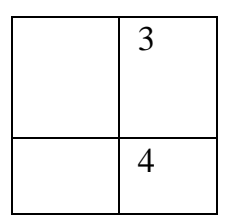

b) Size

a) Weight

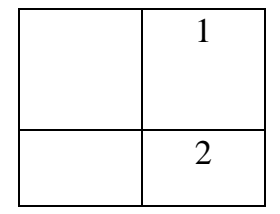

c) BMI result

1) Low weight $<18.5$

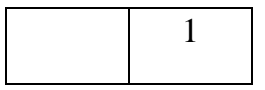


2) Normal $[18.5-25\rangle$

3) Overweight $\geq 25$

\begin{tabular}{|c|c|}
\hline & 2 \\
\hline & 3 \\
\hline
\end{tabular}

F. Results of smear microscopy
a) $\mathrm{BK}(+)$

\begin{tabular}{|l|l|}
\hline & 1 \\
\hline
\end{tabular}
b) $\mathrm{BK}(++)$

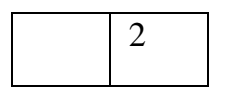
c) $\mathrm{BK}(+++)$

\begin{tabular}{|l|l|}
\hline & 3 \\
\hline
\end{tabular}

G. Cultivation result
a) Cultivation
(+)

\begin{tabular}{|l|l|}
\hline & 1 \\
\hline
\end{tabular}
b) Cultivation $(++)$

\begin{tabular}{|l|l|l|}
\hline & 2 & $\begin{array}{l}\text { c) Cultivation } \\
(+++)\end{array}$
\end{tabular}

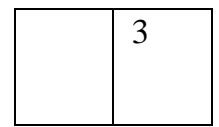

H. CONDITION OF ENTRY:

TREATED
a) BEFORE TREATED
b) NEVER

I. Result of number of drugs with resistance IN VITRIO (PS)

\begin{tabular}{|l|l|l|l|l|l|l|l|l|l|l|l|l|l|}
\hline 1) Resistance & $\mathrm{R}$ & $\mathrm{H}$ & $\mathrm{Km}$ & $\mathrm{Am}$ & $\mathrm{Cm}$ & Lfx & Mfx & Eto & Cs & PAS & Cfz & Amx/Clv & Cpx \\
\hline (R) & & & & & & & & & & & & & \\
2) Sensitive \\
(S) \\
(Mark with \\
X)
\end{tabular}

J. Haematocrit result

a) Result

b) Men: Normal: <41\% - 53\%>

Low: $<41 \%$

c) Women: Normal: $<36 \%-46 \%>$

Low: $<36 \%$

\begin{tabular}{|l|c|}
\hline & 1 \\
\hline & 2 \\
\hline & 1 \\
\hline & 2 \\
\hline
\end{tabular}


II. Risk factor associated with TB- XDR-TB-MDR cases and controls

\begin{tabular}{|r|l|l|l|}
\hline 2.1. & Internal case factors and controls & Yes(1) & No (0) \\
\hline & A. Harmful Habits & & \\
\hline 2 & Consumed alcohol more than 3 times per week & & \\
\hline 3 & Consumed more than 5 cigarettes per week & & \\
\hline & B. History of comorbidities & & \\
\hline 4 & Showed positive serology for HIV & & \\
\hline 5 & Diabetes Mellitus & & \\
\hline 6 & Prior use of corticosteroid therapy & & \\
\hline & C. History of Tuberculosis Treatment & & \\
\hline 7 & You were previously treated for tuberculosis / MDR-TB & & \\
\hline 8 & Showed poor adherence to TB/MDR-TB treatment & & \\
\hline 9 & You were on TB/ MDR-TB treatment for less than 1 year & & \\
\hline 10 & You failed the primary, individualized TB/TB-MDR-TB regimen & & \\
\hline 11 & You have previously stopped treatment for TB/MDR-TB. & & \\
\hline 12 & Had early relapse within 6 months of being discharged as cured of TB/MDR- & & \\
\hline 13 & PBevious use of Fluoroquinolones & & \\
\hline 14 & You received self-administered home treatment for TB- /TB- MDR. & & \\
\hline 15 & Had adverse reactions to anti-tuberculous treatment (RAFA). & & \\
\hline 2.2 & External case-control factors & Yes(1) & No \\
\hline & D. History of intra- and extra-home contact & & \\
\hline 16 & Had a family member at home with TB -XDR/TB - MDR & & \\
\hline 17 & Had family members who died of XDR-TB/MDR-TB & \\
\hline 18 & Have you had neighbors or friends in the neighborhood with tuberculosis? & & \\
\hline 19 & Have you had neighbors or friends in the neighborhood who died from TB? & & \\
\hline 20 & History of incarceration in a correctional facility within the last two years & & \\
\hline 21 & Previously worked in a hospital or was a health science student & & \\
\hline 22 & He was hospitalized in the last two years before getting sick with TB, for & & \\
\hline & more than 15 days. & & \\
\hline
\end{tabular}

